chest wall was an additional indication for sternal elevation in 47 patients. All patients had at least 2 bars placed for repair, and $33 \%$ had a third bar. Median operative time for MIRPE with Rultract was 122 minutes (range 45-274 minutes). There were no intraoperative complications. Two patients had ecchymosis at the site of bone clamp insertion that resolved without sequelae.

\section{DISCUSSION}

Visualization and dissection across the mediastinum in patients with severe excavatum is impaired by the inwardly displaced sternum. Forced mechanical elevation increases the anteroposterior dimension and facilitates dissection and visualization. Expanding the retrosternal space has been recommended by others to minimize pericardial trauma and eliminate cardiac perforation..$^{2-4}$ Other techniques require large incisions or blind dissection, although Yoon and colleagues ${ }^{5}$ have reported the use of wire stitches in the sternum.

We present a simple technique that requires minimal additional incisions or dissection to elevate the sternal deformity. This technique provides increased visualization and reduces stress on the intercostal spaces during bar insertion and rotation. Our use of forced sternal elevation has increased with experience, and this technique is now used in most adult MIRPE cases. We believe that this technique can facilitate safe dissection and bar passage as well as reduce the risk of intercostal muscle stripping in adult patients undergoing MIRPE.

We acknowledge Jesse Lackey for his contributions.

\section{References}

1. Bouchard S, Hong AR, Gilchrist BF, Kuenzler KA. Catastrophic cardiac injuries encountered during the minimally invasive repair of pectus excavatum. Semin Pediatr Surg. 2009;18:66-72

2. Johnson WR, Fedor D, Singhal S. A novel approach to eliminate cardiac perforation in the Nuss procedure. Ann Thorac Surg. 2013;95:1109-11.

3. Takagi S, Oyama T, Tomokazu N, Kinoshita K, Makino T, Ohjimi H A new sternum elevator reduces severe complications during minimally invasive repair of the pectus excavatum. Pediatr Surg Int. 2012; 28:623-6.

4. Tedde ML, de Campos JR, Wihlm JM, Jatene FB. The Nuss procedure made safer: an effective and simple sternal elevation manoeuvre. Eur J Cardiothorac Surg. 2012;42:890-1

5. Yoon YS, Kim HK, Choi YS, Kim K, Shim YM, Kim J. A modified Nuss procedure for late adolescent and adult pectus excavatum. World J Surg. 2010; 34:1475-80.

\title{
Minimizing chest wall trauma in single-port video-assisted thoracic surgery
}

\author{
Calvin S. H. Ng, MD, FRCS(CTh), Randolph H. L. Wong, MBChB, FRCS(CTh), \\ Rainbow W. H. Lau, MBChB, MRCS, and Anthony P. C. Yim, DM, FRCS, Hong Kong, China
}

Single-port video-assisted thoracic surgical (VATS) major lung resection for early stage lung cancer was first reported in 2011 by Gonzalez's group in Spain. ${ }^{1}$ This was a significant milestone and revolutionized the way VATS surgeons can further reduce access trauma by using only 1 incision port for lung resection. ${ }^{2}$ The success and adaptability of the single-port techniques in the treatment of various thoracic diseases have made them hugely popular around the world. ${ }^{3,4}$

\footnotetext{
From the Department of Surgery, Prince of Wales Hospital, The Chinese University of Hong Kong, Hong Kong, China.

Disclosures: Authors have nothing to disclose with regard to commercial support.

Received for publication Aug 6, 2013; revisions received Oct 15, 2013; accepted for publication Oct 25, 2013; available ahead of print Dec 2, 2013.

Address for reprints: Calvin S. H. Ng, MD, FRCS(CTh), Division of Cardiothoracic Surgery, The Chinese University of Hong Kong, Prince of Wales Hospital, Shatin,

NT , Hong Kong SAR, China (E-mail: calvinng@surgery.cuhk.edu.hk).

J Thorac Cardiovasc Surg 2014;147:1095-6

$0022-5223 / \$ 36.00$

Copyright (c) 2014 by The American Association for Thoracic Surgery

http://dx.doi.org/10.1016/j.jtcvs.2013.10.043
}

Despite minimal access approaches, thoracic surgical patients continue to be affected by significant acute and chronic postoperative pain. ${ }^{5}$ To address this problem, at least in part, we have previously described our maneuvers in minimizing chest wall trauma in conventional VATS, and these are also applicable to single-port VATS. ${ }^{5}$ Relative to conventional 3-port VATS, the single-port VATS technique is associated with fewer incisions and potentially less injury to fewer intercostal nerves. However, to fit all the instruments through 1 small incision and to allow them to reach the upper and lower extremes of the thoracic cavity during single port surgery, significant instrument torquing and nerve injury may occur. We have found the following useful to reduce port site trauma in our single port VATS lung resection practice:

1. We routinely use a $120^{\circ}$ thoracoscope, which allows magnified and unparalleled vision for the whole thoracic cavity. More importantly, the excellent field and degree of vision obviate the need to torque the thoracoscope in the single-port incision, which may reduce intercostal 


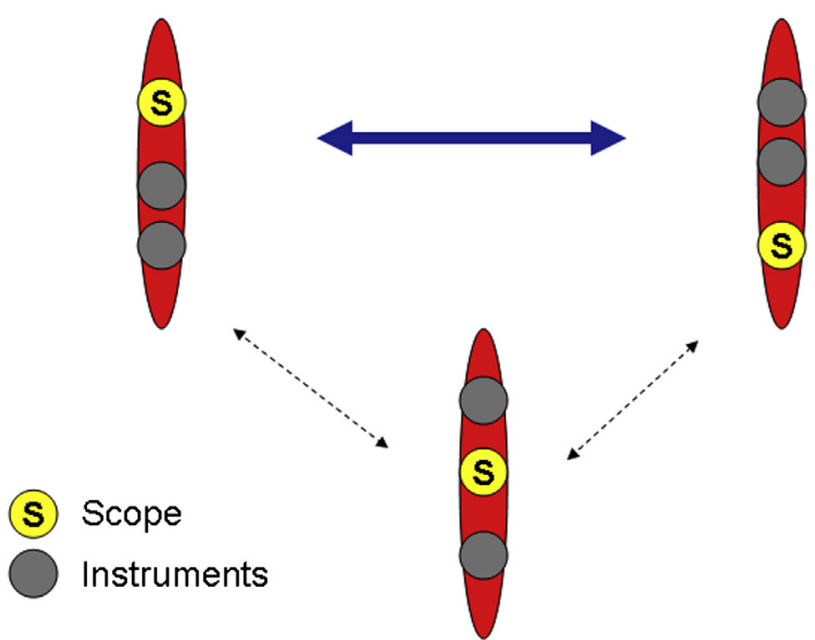

FIGURE 1. Illustration showing the change in order of instruments for single-port video-assisted thoracic surgical lung resection, which may improve access and facilitate the procedure.

nerve injury. An inherent difficulty in single-port VATS is the visualization of the tip and exit site of the stapler anvil. This can be overcome by the $120^{\circ}$ scope, which allows the surgeon to "look back on himself or herself" as well as at the stapler anvil exit site. Previous reports have noted that $30^{\circ}$ scopes are adequate for those experienced in single-port surgery, however, the more advanced technology may be more useful for those still on the learning curve. ${ }^{1,3}$

2. Often the single-port surgeon may find visualization and dissection of structures, as well as finding the correct angles for endostapler deployment, difficult. Changing the order of the instruments along the single-port incision (Figure 1) can sometimes help facilitate these maneuvers, without the need to enlarge the incision or exert force on the wound. During most of the dissection, the scope is placed at the posterior aspect of the incision. It is noteworthy that placement of the scope in the middle position is less often used because it is then "floating" in the incision wound, which makes keeping the camera steady difficult.

3. Angulated and narrow-shaft double-hinged instruments and flexible endostaplers have become part of the essential armamentarium for single-port VATS surgeons. These designs allow more room for instrument manipulation, reduce instrument fencing, decrease the need for torquing, permit difficult stapling angles, and allow smaller incisions to be made. When used with the very-wide angle thoracoscopes, they allow the transformation from an essentially linear instrumentation plane (all instruments inserted through a linear slit incision) to the ability of instrument placement to take advantage of the 3-dimensional intrathoracic cavity

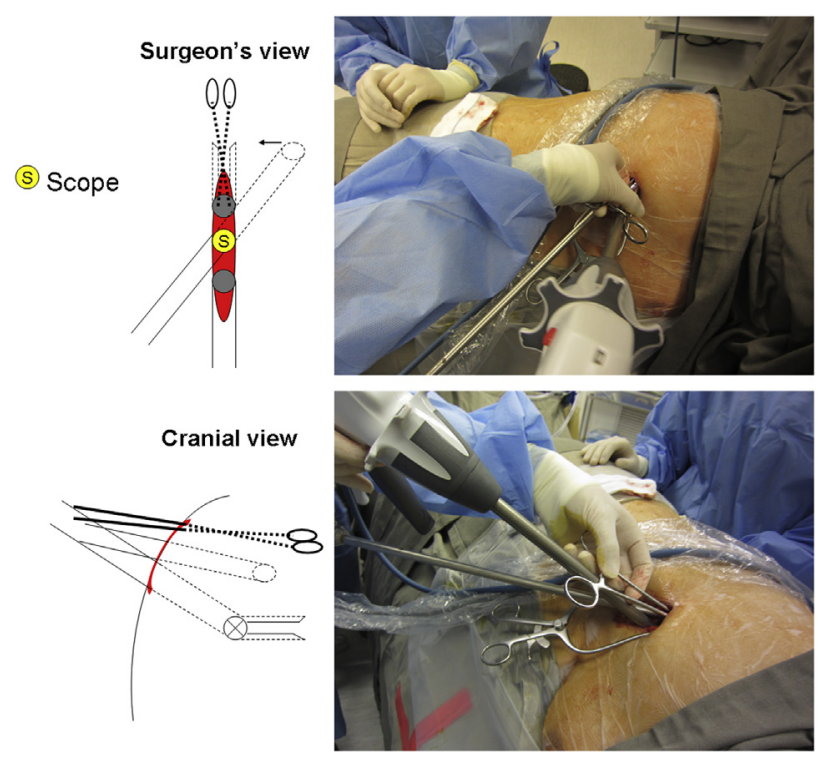

FIGURE 2. Single port video-assisted thoracic surgical right upper lobectomy seen from 2 views. In the surgeon's view, the scope is lying obliquely, viewing angle at $110^{\circ}$ (arrow) to create room in the central aspect of the pleural cavity for the endostapler and sponge forceps. In the caudal view, the flexible function of the endostapler is fully used to make the desirable stapling line while minimizing fencing and interference with the other instruments.

(Figure 2). The full exploitation of the intrathoracic space also reduces instrument fencing and improves stapling angles.

It is from these principles that manufacturers are developing thinner $120^{\circ}$ thoracoscopes, narrow-shaft thoracoscopic instruments, and more flexible endostaplers for single-port VATS surgery. The combination of these more specialized instruments, rather than any individual invention, may be the key to facilitating single-port VATS. These are encouraging times for single-port VATS, and indeed for VATS in general, because a new surgical approach challenges the boundaries of technologic advancement and makes us rethink our strategies to minimize chest wall trauma. Future randomized studies are needed to investigate potential benefits of the singleport approach.

\section{References}

1. Gonzalez D, Paradela M, Garcia J. Dela Torre M. Single-port video-assisted thoracoscopic lobectomy. Interact Cardiovasc Thorac Surg. 2011;12:514-5.

2. Ng CS, Lau KK, Gonzalez-Rivas D, Rocco G. Evolution in surgical approach and techniques for lung cancer. Thorax. 2013;68:681.

3. Gonzalez-Rivas D, Paradela M, Fieira E, Velasco C. Single-incision video-assisted thoracoscopic lobectomy: initial results. J Thorac Cardiovasc Surg. 2012;143: 745-7.

4. Ng CS. Uniportal VATS in Asia. J Thorac Dis. 2013;5(Suppl 3):S221-5.

5. Yim AP. Minimizing chest wall trauma in video-assisted thoracic surgery. J Thorac Cardiovasc Surg. 1995;109:1255-6. 